\title{
Experiences in the application of the Flipped Learning model in a Music Technology course
}

\section{Experiencias en la aplicación del modelo Flipped Learning en un curso de Tecnología Musical}

\author{
José Urgilés $^{1}$ (D), Galo Carrión ${ }^{1}$ (i), Verónica Pinos-Vélez ${ }^{2}$ (D), Victoria Abril-Ulloa ${ }^{3}$ (D), Karina \\ Quinde-Herrera ${ }^{4}$ iD \\ 1 MediaLab Facultad de Artes, Universidad de Cuenca, Cuenca, Ecuador. \\ ${ }^{2}$ Facultad de Ciencias Químicas, Universidad de Cuenca, Cuenca, Ecuador. \\ ${ }^{3}$ Carrera de Nutrición y Dietética, Facultad de Ciencias Médicas, Universidad de Cuenca, Cuenca, Ecuador. \\ ${ }^{4}$ Dirección de Investigación, Universidad de Cuenca, Cuenca, Ecuador. \\ Autores para correspondencia: karina.quinde@ucuenca.edu.ec \\ Fecha de recepción: 17 de mayo de 2019 - Fecha de aceptación: 6 de septiembre de 2019
}

\begin{abstract}
The increasing use of information and communication technologies (ICTs) modified many tasks and strongly altered our behaviors. Having this in mind, the Flipped Learning (FL) model provides a promising learning alternative that links the learning environment with the student's behavior while altering the traditional instruction model. The FL model involves activities in which students individually review online materials and develop projects and assignments in groups and on-site. The objective of this study was to evaluate the flipped learning model in arts education, more precisely how the introduction of this model affects the learning of the students from the University of Cuenca attending the course of music technology. The findings of this study highlighted the benefits of active learning and the acceptance of the material developed for the implementation of the FL model. Notwithstanding, the overall positive evaluation of the FL approach, the authors suggest carrying out more studies, involving a larger student population, to better identify and remedy remaining obstacles, what will facilitate the use of the FL model in other courses.
\end{abstract}

Keywords: ICTs, flipped learning, music technology, Ableton Live.

\section{RESUMEN}

El uso creciente de las tecnologías de la información y la comunicación (TIC) ha modificado muchas tareas y sobre todo alterado nuestro comportamiento. En este contexto, el modelo Flipped Learning (FL) ofrece una alternativa de aprendizaje prometedora que vincula el entorno de aprendizaje con estos nuevos comportamientos del estudiante al modificar el modelo de instrucción tradicional. El modelo FL incluye actividades en las que los estudiantes revisan individualmente material en línea y desarrollan proyectos y tareas en grupos en las aulas. El objetivo de este estudio fue evaluar el modelo de aprendizaje invertido en educación artística, específicamente cómo la introducción de este modelo afecta el aprendizaje de los estudiantes de la Universidad de Cuenca que asisten al curso de tecnología musical. Los resultados de este estudio destacan los beneficios relacionados con el fomento del aprendizaje activo y la aceptación del material desarrollado para la implementación del modelo FL. A pesar de la evaluación positiva general del enfoque de FL, los autores sugieren que se realicen más estudios, con una población estudiantil más numerosa, para remediar los inconvenientes identificados durante el proyecto, lo que facilitará el uso del modelo de FL en otros cursos.

Palabras clave: TICs, modelo invertido, curso tecnología musical, Ableton Live.

\section{INTRODUCTION}

Since the end of the $20^{\text {th }}$ century, the development of information and communication technologies (ICTs), the rapid proliferation of mobile devices, and the spread of Internet changed our style and methods of communication and work. In particular, these developments affect the way we create, consume, and share content. These changes also modified learning dynamics and the ways students learn. For example, in recent years, universities worldwide adopted several types of online education. In addition, numerous open learning platforms enable users today to learn or refresh their knowledge without attending educational centers. Certain of these platforms even received certification that attests the learning quality of those methods.

In this context, educational institutions have been forced to redefine their assumptions regarding the teaching and 
learning processes (Garrison \& Kanuka, 2004) and to adapt to these new scenarios. The adjustment has been necessary because a large percentage of today's students belong to a generation whose behavior and learning stylehave been modified by the emergence of Internet, mobile devices, and ICT. In Ecuador, for example, with a population in 2019 of 16.7 million, Internet penetration has reached $80 \%, 11$ million individuals (64\%) actively use social media, and 12.25 million access the Internet using a mobile device (Hootsuite Media Inc., n.d.). Against this background, several education models, such as blended learning (BL), saw daylight to introduce new ways of accessing knowledge through modifying the traditional learning model and by taking advantage of online resources.

Most courses promote the traditional classroom configuration, in which concepts, facts and historic events are introduced in face-to-face sessions, complemented by assignments that are meant to be completed at home; enhancing passive learning. In addition, traditional instructors can become complacent and turn learning into memorizing terminology instead of helping students comprehend such terminology (Mennella, 2016). Blended learning (BL) or flipped learning (FL) models increase the efficiency of class time and learning activities, and achieve high levels of learning, mostly through personalized student assignments (Sams \& Bergmann, 2013). BL can be defined as "the thoughtful integration of classroom face-to-face experiences with online learning experiences" (Garrison \& Kanuka, 2004). On the other hand, Mennella (2016) defines FL as "a pedagogical approach to teaching and learning in which the initial exposure to course content occurs at home before the students come to class, typically provided through online videos".

Given the complexity of BL and its resource requirements, the implementation, design, and application of $\mathrm{BL}$ represents a challenge for professors and institutions. Studies on BL provide basic information on the development of the online or pre-class stage as well as the face-to-face stage or classes, while studies on FL present a more detailed description and interaction of the two stages (Lee, Lim, \& Kim, 2016). The two essential components of FL are the pre-class stage, which involves the use of the Internet and a class component, i.e., face-toface interaction. An important challenge is to effectively integrate the two components. To this end, a reconceptualization and reorganization of teaching and learning dynamics are essential (Garrison \& Kanuka, 2004).

Several studies define the flipped classroom and FL in similar ways (Fidalgo-Blanco, Martinez-Nuñez, BorrásGene, \& Sanchez-Medina, 2017; Kim, Heo, \& Lee, 2015). This overlap largely occurs because "flipping" the class results in activities outside the classroom and consists mainly in sharing knowledge (e.g., the professor's presentation of material), whereas in-class activities revolve around understanding the subject and cooperation among student pairs (Fidalgo-Blanco et al., 2017). However, the FL model involves a deeper integration of the pre- and in-class components in which the main concepts align with the knowledge that is imparted. As a result, students develop at their own pace while adopting self-directed learning, and active interaction occurs between students and professors (Kim, Kim, Cho, \& Jang, 2017). FL is also considered to be an extension of the flipped classroom, which includes a more active and collaborative environment (O'Connor et al., 2016). In addition, according to Hussey, Richmond, \& Fleck (2015), development of materials can occur according to Bloom's taxonomy (Fig. 1). Thus, activities that involve lower levels of learning (i.e., remembering or understanding) are assigned for completion during the pre-class, whereas activities that involve higher levels of learning (i.e., evaluating or creating) are undertaken during the face-toface stage.

The Flipped Learning Network (n.d.) proposes four fundamental pillars of the FL model. First, creating a flexible environment that facilitates a variety of learning modes in which professors create flexible spaces and provide support in group work as well as on individual assignments. Second, creating a student-centered learning culture that facilitates the active construction of knowledge. The third pillar involves using intentional content, which means prioritizing concepts used in direct instruction, creating or organizing relevant content

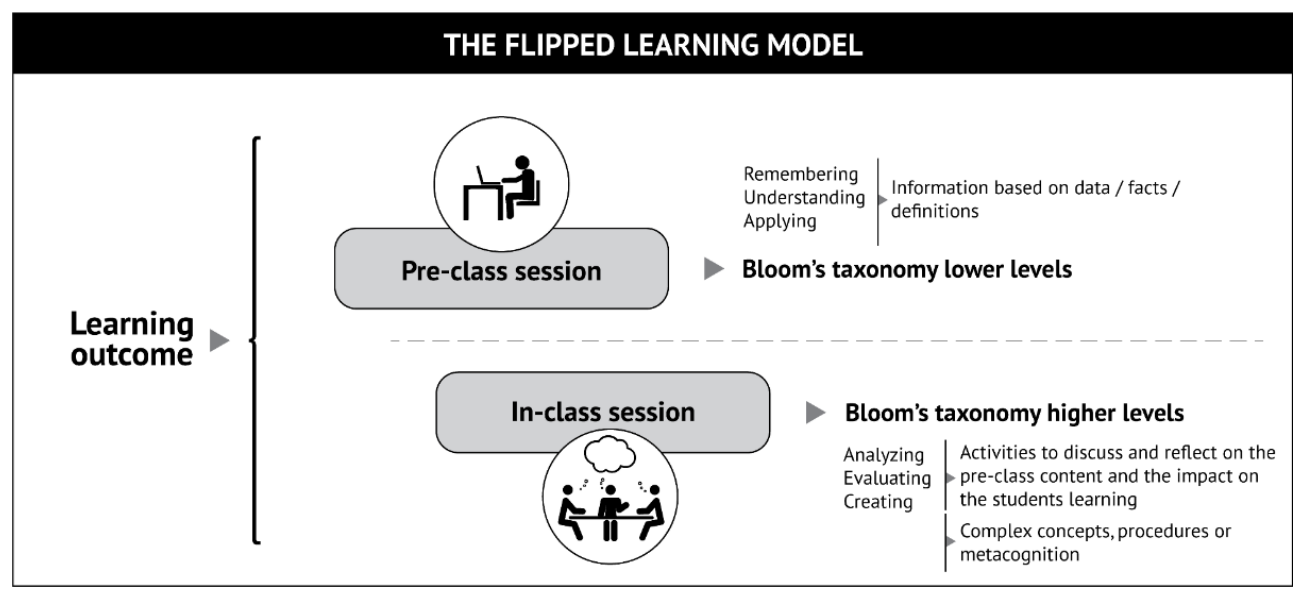

Figure 1. The Flipped Learning Model. The main objective within the model is to liberate time in the in-class session to be used in group activities to discuss, reflect and learn complex concepts, procedures or metacognition processes. Adapted from Hussey et al. (2015). 
(videos) and providing materials that are accessible and relevant to students. Finally, the last pillar focuses on establishing the professional role of the educator, such as being available and providing feedback to students (individually or in groups), promoting formative assessments, and collaborating with other colleagues to transform the educator's practice.

Flipped Learning has been applied in some courses of university education such as English, informatics, and specific subjects of medicine and nursing among others (Heeseung et al., 2015; Noor-Akmal, 2016; O'Connor et al., 2016; Oh, Kim, Kim, \& Vasuki, 2017; Pence, 2016). In these studies, advantages found when FL was applied were more engagement in the course, self-regulation and more motivation in comparison with regular classes. Few studies on the application of the FL model in arts courses were found. Therefore, in this article, we present our experiences using the model in a music technology course taught between March and July 2017. Our study investigated the use of the digital audio workstation (DAW) Ableton Live 9 to produce sound in a linear and nonlinear format for live recordings and final cuts. This article presents the results of the FL approach through preand posttests, and a questionnaire aiming to evaluate the effect of FL halfway the course.

\section{MATERIALS AND METHODS}

A nonprobability sample was chosen based on the availability of the course within the degree program. Classes lasted 16 weeks and consisted of two hour-long, face-to-face sessions and an estimated two hours of preclass work per session. The study population consisted of a group of seven students, each of whom had access to a personal computer. The two educators who developed the materials for each lesson of the semester-long course participated in the application of the inverted model.

Initially, a survey was administered and based on a questionnaire by Humante-Ramos, García-Peñalvo, \& Conde-González (2016), previously developed by MarínJuarros (2014). The questionnaire was used to obtain data about the characteristics and behavior of the students regarding their use of ICTs. The collected information was used in the design of the course. For the quasiexperimental part of the study aiming to evaluate student progress, the questionnaire on prior knowledge was administered at the beginning and at the end of the course as a pre and post-test. This questionnaire was prepared for the educators in charge of the course and its content was structured in three thematic groups: general concepts of digital audio, methods for the use of software interfaces, and protocols for the use of hardware. Both questionnaires were applied online but during class time. In addition, the questionnaire to assess the FL effect was administered during Week 12 of the course so that students could - after a few weeks of experience - evaluate the activities used in this model. We used a Likert scale of 1 to 5 to measure the response to the set of questions ( $1=$ not at all; $5=$ entirely). The structure of the class for Flipped Learning was planned on two levels: by semester and per lesson (Lee $e t$ al., 2016). The design of materials for the semester considered the objectives of the course, the general topic of each lesson, the learning strategies, the design of activities, the orientation guide for the course, and the approach to evaluation. Each lesson incorporated an online component, the "pre-class," and an in-person component, i.e., "class." Planning at this level was based on each of the learning goals determined for each session within the syllabus while seeking integration between the two components; Table 1 shows the learning themes of the course and its organization.

Table 1. Organization of topics for the semester by class.

\begin{tabular}{ll}
\hline Week number & Topic \\
\hline $1-3$ & Interface operation \\
$4-5$ & Software tools \\
$6-7$ & Development of the practical project \\
8 & Midterm examination \\
$9-12$ & Software tools \\
$13-15$ & Development of the final project \\
16 & Final examination \\
\hline
\end{tabular}

Based on Lee et al. (2016), the pre-class materials were developed in three stages, respectively in stage 1 creating the materials/drafting the script, stage 2 recording, and stage 3 video editing and technical aspects. After creating the scripts, the team produced videos in two formats. The first involved tutorial screenshots and an audio explanation from the professor. The second format was recorded using two cameras, one for the professor explaining the content of the pre-class and one for screenshots on the hardware and software use. Regarding the technical characteristics of the videos, the content was established according to each module and subject. The time duration of each video was limited to eight minutes, considering the recommendation of a maximum duration of 20 minutes (Mason, Shuman, \& Cook, 2013; Smith \& McDonald, 2013; Goodwin \& Miller, 2013). Speed control and the different video resolutions could be used through YouTube (Bush, 2013). Any sound that could cause distractions was removed during editing to improve the listening experience (Mason et al., 2013; Smith \& McDonald 2013).

The project team choose Moodle as the course management system (CMS) because of its features and the needs and policies of the University of Cuenca (Universidad de Cuenca) (GNU, General Public License, and Open Source). The pre-class and class organization is listed in Table 2. The pre-class was organized into two sections: materials and evaluation. The materials were the

Table 2. Pre-class and class organization.

\begin{tabular}{ll}
\hline Pre-class & Class \\
\hline 1. Material: video & 1. Introduction: a review of online materials \\
2. Evaluation: Questionnaire/forum & 2. Main activity \\
3. Extra resources: bibliography or & 2.1. Student activity: practical application of knowledge \\
relevant articles & 2.2. Professor activity: active guidance and provision of feedback to the students \\
& 3. Programming: review and guidance for upcoming activities
\end{tabular}


videos specifically produced for the course and other resources, such as relevant websites and readings recommended for each lesson. The corresponding assessment was based on three types of online activity: forums, questionnaires, and assignments that included uploading files to the course platform. In turn, each class consisted of three parts, respectively: the synthesis of online materials, the main activity, and instructions regarding the next pre-class assignments. The main activity promoted working on the higher levels of Bloom's taxonomy and focused on composing, playing, and recording a song using the software tools taught in class. This activity involved two essential strategies to promote active learning: assignments based on problems and projects. Each class presented the challenge of completing a part or element of a song, which the students had to resolve using the knowledge acquired in their preclass work. The goal of the course was to plan, design, and produce an original song.

Additionally, feedback strategies were established through individual tutoring to clarify questions for each project. Given the individual nature of working with the software, we also promoted activities that encouraged the students to complete exercises and resolve difficulties in pairs.

\section{RESULTS}

The students in the course were predominantly male and 20 years old on average. They were consulted about the use of Internet, social applications, and technological tools. $85.7 \%$ of the students indicated that they used cell phone and laptop; $28.6 \%$ indicated using these devices between 3-6 hours weekly and $71.4 \%$ over 7 hours weekly. Concerning the use of social media, all students used the most popular social networks, such as Facebook and Twitter, as well as chat platforms, email, and tools to share video and audio. SoundCloud was the online platform students used to share audio. That means that the students possessed or could access the devices and resources for completing the pre-class tasks and that they were knowledgeable how to use them. For students unable to access the Internet at home, laboratory hours were extended by two hours per week. One student reported a degree of visual impairment and was therefore assigned a computer with a screen-magnification capability.

The questionnaire to assess the FL effect (Table 3) yielded an overall favorable judgment of $83.4 \%$; students indicated that the professor clearly explained the objectives and the learning method to be used at the beginning of the course. Concerning the use of tools, $91.6 \%$ of students affirmed that the professor used different technological media in the master class while they took notes. Regarding the development of the course, $81.7 \%$ reported that the professor encouraged questions and group discussion. A less favorable result $(50 \%)$ concerns the incentive to work in group to create research projects or solve problems. This result could be explained by the nature of the assignment, which was focused on the individual use of a computer to learn specific software tools. Student satisfaction is important to create a positive learning environment and positive performance (Kim et $a l ., 2017)$. Results indicate that $71.4 \%$ of the participating students were satisfied with the application of the FL model in both, the pre-class and class.

Focus group discussions about the FL experience revealed that most students $(58.3 \%)$ invested 120 minutes or more to activities outside the classroom, while $41.7 \%$ invested between 30 and 60 minutes. It is important to highlight that the maximum amount of time allotted for autonomous work in the curriculum was two hours. Only $8.3 \%$ of students invested up to four hours. Given the nature of the course, classes were developed by two professors. One was in charge of the detailed knowledge regarding the software tools and interface. The other was in charge of the application of that knowledge to create music. The students positively evaluated the professors' participation because their focus areas were complementary. Similarly, the students referred positively to the personal treatment and the approach to problem-solving in the FL model. In addition, they mentioned the importance of constant communication with the professors through the virtual platform and during class sessions.

At the beginning of the semester, an average score of $13.8 / 26$ was obtained, while at the end of the course this score rose to $20.7 / 26$. The differences between the preand post-test scores for the course material were significant different, obtaining a Student's t-test result of

Table 3. Questionnaire on the impact of FL, $\%$ (Likert scale: $1=$ not at all; $5=$ entirely).

\begin{tabular}{lccccc}
\hline Item & \multicolumn{5}{c}{ Likert scale } \\
\cline { 2 - 5 } & 1 & 2 & 3 & 4 & 5 \\
\hline $\begin{array}{l}\text { The professor clearly explains the goals and objectives } \\
\text { during the first meeting. }\end{array}$ & 0 & 8.3 & 8.3 & 16.7 & 66.7 \\
$\begin{array}{l}\text { The professor teaches the master class without the use of } \\
\text { technology, and the student's activity is to take notes. }\end{array}$ & 0 & 33.3 & 16.7 & 16.7 & 33.3 \\
$\begin{array}{l}\text { The professor teaches the master class using different } \\
\text { technologies, and the student's activity is to take notes. }\end{array}$ & 8.3 & 0 & 0 & 8.3 & 83.3 \\
$\begin{array}{l}\text { The professor provides course notes and the teaching } \\
\text { material to be reviewed before class. }\end{array}$ & 0 & 8.3 & 0 & 41.7 & 50 \\
$\begin{array}{l}\text { The professor encourages students in the classroom to } \\
\text { actively participate through questions and discussion } \\
\text { groups. }\end{array}$ & 8.3 & 0 & 0 & 25.0 & 66.7 \\
$\begin{array}{l}\text { The professor encourages working in groups to create } \\
\text { research projects or to solve problems. }\end{array}$ & 25 & 16.7 & 8.3 & 16.7 & 33.3 \\
$\begin{array}{l}\text { The professor stimulates individual work to create case } \\
\text { studies, portfolios, and literature analysis. }\end{array}$ & 0 & 0 & 16.7 & 25 & 58.3 \\
\hline
\end{tabular}


$\mathrm{p}=0.007(<0.05)$. The questions that presented difficulties for the students are related to the protocols for using the hardware, such as the connection to the sound card or the MIDI controller. Regarding the use of the software interface, difficulties came forward in the advanced use of specific tools, primarily audio effects and filters.

\section{DISCUSSION}

The study highlights the benefits and challenges in the application of the FL model in a music technology course, whose main objective was to teach the basic knowledge students require to use digital audio workstation tools to create linear format projects and live performances. In generally, the application of the model enhanced active learning in the application of these tools to create music. The students positively evaluated the design, resources, and materials used during the course. Although similar projects did not achieve improved student performance (Fidalgo-Blanco, Martinez-Nuñez, Borrás-Gene, \& Sanchez-Medina, 2017; Mennella, 2016), we noted a significant improvement in the response to the knowledge questionnaires between the pre- and post-test. However, in future studies, it will be necessary to expand the sample and use other evaluation instruments, such as grades for each assignment and testing throughout the course. Objectively, the improvement we noted could be due to the nature of the subject and the students' predisposition to use technological tools. According to Kim et al. (2015), a positive attitude regarding technology results in an improved self-efficacy in students.

Regarding the face-to-face sessions, it was observed that the number of group activities required by the FL model to foster active learning was insufficient. This failing was due to the nature of the subject, which required the individual use of software and hardware, such as headphones. Therefore, we recommend including additional activities that involve working in pairs, such as partially developing the project through discussion and consensus or group review activities.

Among the challenges that emerged, we can mention the number of resources required to prepare the pre-class. This project had four professors and a research assistant. Two professors developed the materials at the macro and micro levels, managed the virtual classroom, and taught the class while the other two professors and the research assistant were responsible for producing the teaching and audiovisual materials. Thus, the instructors were required to possess basic knowledge of developing audiovisual materials and the use of production and postproduction tools. In addition, a considerable amount of time was required to develop the entire course, particularly during the initial stage. A gradual implementation of the FL model represents a possible means to reduce the time required to develop the pre-class materials. Such an approach would also facilitate designing the course based on students' reactions (Murphy, Chang, \& Suaray, 2016). Furthermore, if the educational institution could provide the necessary technical support, the professors would have more time to develop their own materials with the necessary quality. In this regard, a guide for the implementation of the FL model was developed as part of this project. The guide includes methodological recommendations for tools that are easy to acquire and use, such as mobile devices.

Finally, given the lack of studies on the application of the FL model in art courses, this study represents a reference for the application and assessment of the model in such fields. Despite the difficulty of creating the materials for the pre-class segments, the promotion of the FL model among educators is relevant because it creates the opportunity to enhance active learning.

\section{ACKNOWLEDGEMENT}

The research was financially supported by the Dirección de Investigación de la Universidad de Cuenca (DIUC). The authors like to thank Daniel López for his collaboration and expertise in implementing the class.

\section{REFERENCES}

Bush, M. D. (2013). Educational technology points of inflection: what MOOCs, flipped classrooms, and OLPC teach us about individualization of learning. Educational Technology, 53(6), 60-63.

Fidalgo-Blanco, A., Martinez-Nuñez, M., Borrás-Gene, O., \& Sanchez-Medina, J. J. (2017). Micro flip teaching - An innovative model to promote the active involvement of students. Computers in Human Behavior, 72, 713-723. https://doi.org/10.1016/j.chb.2016.07.060

Flipped Learning Network. Definition of Flipped Learning. (n.d.). Retrieved from https://flippedlearning.org/definition-of-flippedlearning/

Garrison, D., \& Kanuka, H. (2004). Blended learning: Uncovering its transformative potential in higher education. The Internet and Higher Education, 7(2), 95-105. https://doi.org/10.1016/j.iheduc.2004.02.001

Goodwin, B., \& Miller, K. (2013). Evidence on flipped classrooms is still coming in. Educational Leadership, 70(6), 78-80.

Humante-Ramos, P., García-Peñalvo, F., \& CondeGonzález, M. Á. (2016). Encuesta sobre el uso de Internet, servicios sociales y herramientas tecnológicas de los estudiantes de la carrera de ingeniería en sistemas y computación en la Facultad de Ingeniería de la UNACH [Survey on the use of Internet, social media, and technological tools of students in the computer engineering degree at the School of Engineering of the National University of Chimborazo -UNACH] [Data set]. Figshare. https://doi.org/10.6084/m9.figshare.3413869

Heeseung, C., Jeongeun, K., Kyung-Sook, B., YeonHwan, P., Nam-Ju, L., \& Chanhee, K. (2015). Applying the Flipped Learning Model to an EnglishMedium Nursing course. Journal of Korean Academy of Nursing, 45(6), 939-48.

https://doi.org/10.4040/jkan.2015.45.6.939 
Hussey, H. D., Richmond, A. S., \& Fleck, B. (2015). A primer for creating a flipped psychology course. Psychology Learning \& Teaching, 14(2), 169-185. doi:10.1177/1475725715592830

Hootsuite Media Inc. (n.d.). Digital in 2018 in Southern America. Retrieved from: https://hootsuite.com/es/pages/digital-in-2018

Kim, H. S., Kim, M. Y., Cho, M., \& Jang, S. J. (2017). Effectiveness of applying flipped learning to clinical nursing practicums for nursing students in Korea: A randomized controlled trial. International Journal of Nursing Practice, 23(5), 1-10. https://doi.org/10.1111/ijn.12574

Kim, J. A., Heo, H. J., \& Lee, H. (2015). Effectiveness of flipped learning in Project Management Class. International Journal of Software Engineering and Its Applications, 9(2), 41-46.

Lee, J., Lim, C., \& Kim, H. (2016). Development of an instructional design model for flipped learning in higher education. Educational Technology Research and Development, 65(2), 427-453. https://doi.org/10.1007/s11423-016-9502-1

Marín-Juarros, V. (2014). Modelos de rediseño de acciones formativas en el entorno virtual de enseñanzaaprendizaje [Redesign models for training activities in online teaching and learning]. Tesis doctoral,

Departament de Pedagogia Aplicada i psicología de l'Educació, Universitat de les Illes Balears, 549 pp. Available at

https://www.researchgate.net/publication/273452427_ Modelos_de_rediseno_de_acciones_formativas_en_el_ entorno_virtual_de_ensenanza-

aprendizaje_Diseno_y_experimentacion_de_estrategias _metodologicas_de_integracion_de_los_entornos_insti tucionales_y_abierto

Mason, G. S., Shuman, T. R., \& Cook, K. E. (2013). Comparing the Effectiveness of an Inverted Classroom to a Traditional Classroom in an Upper-Division Engineering Course. IEEE Transactions on Education, 56(4), 430-435.

https://doi.org/10.1109/TE.2013.2249066
Mennella, T. A. (2016). Comparing the efficacy of flipped vs. alternative active learning in a College Genetics Course. The American Biology Teacher, 78(6), 471-479. https://doi.org/10.1525/abt.2016.78.6.471

Murphy, J., Chang, J.-M., \& Suaray, K. (2016). Student performance and attitudes in a collaborative and flipped linear algebra course. International Journal of Mathematical Education in Science and Technology, 47(5), 653-673. https://doi.org/10.1080/0020739X.2015.1102979

Noor-Akmal, S., I. (2016). Effectiveness of team-based learning in teaching medical genetics to medical undergraduates. Malaysian Journal of Medical Sciences 23(2), 73-77.

O'Connor, E. E., Fried, J., McNulty, N., Shah, P., Hogg, J. P., ..., et al. (2016). Flipping radiology education right side up. Academic Radiology, 23(7), 810-22. http://dx.doi.org/10.1016/j.acra.2016.02.011

Oh, J., Kim, S., Kim, S., \& Vasuki, R. (2017). Evaluation of the effects of flipped learning of a nursing informatics course. The Journal of Nursing Education, 56(8), 477-83. https://doi.org/10.3928/0148483420170712-06

Pence, P. L. (2016). Flipping a first-year medicalsurgical associate degree registered nursing course: A 2-year pilot study. Teaching and Learning in Nursing, 11(2), 52-57. https://doi.org/10.1016/j.teln.2015.12.006

Sams, A., \& Bergmann, J. (2013). Flip your students' learning. Educational Leadership, 70(6), 16-20.

Smith, C. M., \& McDonald, K. (2013). The flipped classroom for professional development: Part II. Making podcasts and videos. The Journal of Continuing Education in Nursing, 44(11), 486-487. https://doi.org/10.3928/00220124-20131025-93 